\title{
Fragmentation of Deprotonated Ions of Oligodeoxynucleotides Carrying a 5-Formyluracil or 2-Aminoimidazolone
}

\author{
Yinsheng Wang, Lijie Men, and Shetty Vivekananda \\ Department of Chemistry-027, University of California at Riverside, Riverside, California
}

2-Aminoimidazolone and 5-formyluracil are major one-electron photooxidation products of guanine and thymine in oligodeoxynucleotides (ODNs). Herein we report the HPLC isolation and tandem mass spectrometric characterization of ODNs carrying those types of base modifications. Collision-activated dissociation (CAD) of the deprotonated ODN ions leads to cleavages of the $3^{\prime} \mathrm{C}-\mathrm{O}$ bond adjacent to the modification site, which provides enough information for locating the sites of modification. The cleavage 3' to 5-formyl-2'-deoxyuridine is in contrast to the observation that there is no cleavage $3^{\prime}$ to an unmodified thymidine under similar conditions. In addition we observed that at high charge states, the loss of 5-formyluracil as an anion and the resulting strand cleavage is predominant over cleavages at other sites. (J Am Soc Mass Spectrom 2002, 13, 1190-1194) (c) 2002 American Society for Mass Spectrometry

$\mathrm{O}$ ne-electron oxidation has been implicated in DNA damage induced by ionizing radiation, oxidative stress, and photoirradiation in the presence of photosensitizers [1-3]. In the latter respect, 2-aminoimidazolone (Iz, structure shown in Scheme 1) was found to be a major identified product of guanine cation radical in duplex DNA under aerobic conditions [4]. Likewise, 5-formyl-2'-deoxyuridine (Scheme 1) was identified in the riboflavin- and 2-methyl-1,4-naphthoquinone-sensitized photoirradiation of thymidine $[5,6]$. Both 2-aminoimidazolone and 5-formyluracil are mutagenic base lesions [7-9].

Understanding the fragmentation mechanism of oligodeoxynucleotides (ODNs) is important for the application of tandem mass spectrometry (MS/MS) in the structure elucidation of ODNs carrying the abovementioned and other base lesions induced by environmental and chemical carcinogens. Though other factors, i.e., the sequence context and charge state, can affect the fragmentation of ODNs, it is well recognized that proton transfer from phosphate backbone to DNA base initiates loss of the base and cleavage of the adjacent 3' $\mathrm{C}-\mathrm{O}$ bond, resulting in the formation of $\mathrm{w}_{\mathrm{n}}$ and its complementary $\left[\mathrm{a}_{\mathrm{n}}-\mathrm{Base}\right]$ ions [10-12] (nomenclature follows that proposed by McLuckey and coworkers [13]). Therefore, proton affinities of DNA bases play an important role in the fragmentation of ODNs. Thymidine has the lowest proton affinity in four nucleosides

Published online August 22, 2002

Address reprint requests to Dr. Y. Wang, Department of Chemistry-027, University of California at Riverside, Riverside, CA 92521-0403, USA. E-mail: yinsheng.wang@ucr.edu
$\mathrm{dA}, \mathrm{dG}, \mathrm{dC}$, and $\mathrm{dT}$ [14-16] as determined by the kinetic method [17]. In line with that, strand cleavages were observed $3^{\prime}$ to $\mathrm{dA}, \mathrm{dC}$, and $\mathrm{dG}$, but not $3^{\prime}$ to $\mathrm{dT}$ in ODNs. Moreover, fragmentation studies of ODNs whose active protons are exchanged with deuterons [11, 12] and ODNs whose phosphate protons are replaced with metal ions $[18,19]$ provide additional evidence for the proton transfer from the phosphate backbone to nucleobases.

The above preference of base loss, however, is not observed in the fragmentation of ODNs at high charge states, wherein the loss of adenine was found to be more predominant than the loss of any other bases. Consequently, the strand cleavage occurs more readily 3 ' to adenosine $[13,20,21]$. Those results indicate that the fragmentation of highly charged, deprotonated ODN ions may follow a different mechanism.

Herein we report the isolation and MS/MS characterization of ODNs carrying a 2-aminoimidazolone or a 5 -formyluracil. The motivation for this study is to establish a sensitive structure method for locating the sites of those two types of oxidative lesions in ODNs.

\section{Materials and Methods}

ODNs were purchased from Integrated DNA Technologies (Coraville, IA) and used without further purification. Riboflavin and other chemicals were obtained from Sigma-Aldrich (St. Louis, MO). For the photosensitized reaction, $100 \mathrm{nmol}$ d(ATACCAAA), d(AAACCATA), or d(ATACAAAC) was dissolved in a $1.6 \mathrm{~mL}$ solution of $50 \mu \mathrm{M}$ riboflavin and $50 \mathrm{mM}$ sodium cacodylate ( $\mathrm{pH}$ 7.0). The solution was then transferred to a 
<smiles>Cn1cc(C=O)c(=O)[nH]c1=O</smiles>

5-formyluracil

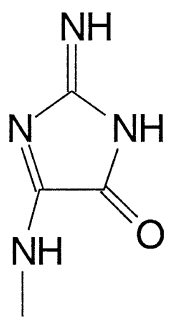

2-aminoimidazolone

Scheme 1

$5.2 \mathrm{~cm}$ i.d. petri-dish, irradiated on ice for one hour under aerobic condition with two 15-W Spectroline light tubes emitting at $365 \mathrm{~nm}$ (Spectronics Corporation, Westbury, NY), and dried by using a Speed-Vac (Savant Instruments Inc., Holbrook, NY). The dried residue was redissolved in water and injected directly for HPLC analysis.

The HPLC separation was carried out on a Surveyor system with a photodiode array detector (ThermoFinnigan, San Jose, CA), and a $4.6^{*} 250 \mathrm{~mm}$ i.d. reverse-phase C18 column (5 $\mu \mathrm{m}$ in particle size, and $300 \AA$ in pore size, Varian, Walnut Creek, CA) was used. The flow rate was $1.0 \mathrm{~mL} / \mathrm{min}$, and a gradient of $5 \mathrm{~min} 0-6 \%$ acetonitrile followed by a $35 \mathrm{~min} 6-21 \%$ acetonitrile in $50 \mathrm{mM}$ triethylammonium acetate $(\mathrm{pH}$ 6.5) was used. The photodiode array detector was set at $260 \mathrm{~nm}$ for monitoring the eluents. The HPLC fractions were then dried by using the Speed-Vac.

Electrospray ionization (ESI)-MS and MS/MS experiments were carried out on an LCQ Deca XP ion-trap mass spectrometer (ThermoFinnigan, San Jose, CA). A solution of $50 / 50(\mathrm{vol} / \mathrm{vol})$ acetonitrile $/ \mathrm{H}_{2} \mathrm{O}$ was used as the solvent for electrospray. A $1 \mu \mathrm{L}$ aliquot of $3 \mu \mathrm{M}$ sample solution was injected in each run. The spray voltage was $4.6 \mathrm{kV}$, and the capillary temperature was maintained at $200^{\circ} \mathrm{C}$. MS/MS was done by selecting the $[\mathrm{M}-2 \mathrm{H}]^{2-}$ or other deprotonated ions as indicated in the text for collisional activation. The mass width for precursor selection was $3 \mathrm{~m} / \mathrm{z}$ units and the collisional gas was helium. Each spectrum was obtained by averaging approximately 50 scans, and the time for each scan was $0.1 \mathrm{~s}$.

\section{Results and Discussion}

\section{Preparation and ESI-MS/MS Characterization of ODNs Containing a 5-Formyluracil}

Initially we were interested in determining the structure of an unidentified major product eluting slower than the starting materials on a reverse-phase column for the riboflavin-sensitized UVA irradiation products of a duplex DNA containing d(TTGGTA) and d(ATACCAAA) [4]. We, therefore, purified the product from the $365 \mathrm{~nm}$ irradiation mixtures of three different ODNs,

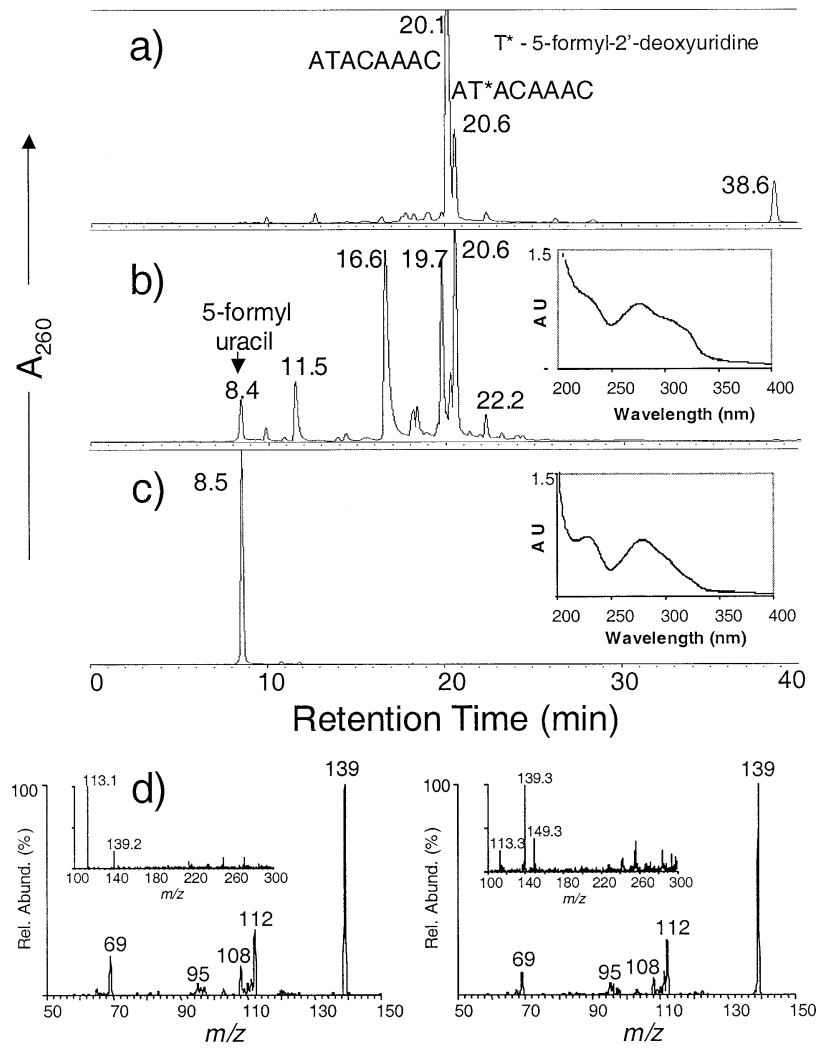

Figure 1. HPLC chromatograms for the separation of: (a) Riboflavin photosensitized photoreaction mixture of d(ATACAAAC), (b) $100{ }^{\circ} \mathrm{C}$ hydrolysis products of $\mathrm{d}\left(\mathrm{AT}^{*} \mathrm{ACAAAC}\right)$, and (c) standard 5-formyluracil. Shown in (d) are the ESI-MS/MS for the $[\mathrm{M}-\mathrm{H}]^{-}$ions of 5-formyluracil isolated from the hydrolysis products of $\mathrm{d}\left(\mathrm{AT}^{*} \mathrm{ACAAAC}\right)$ (left) and the authentic 5-formyluracil (right), the negative-ion ESI-MS for the two samples are shown in the insets. For the hydrolysis reaction, approximately 40 nmol ODN was dissolved in $600 \mu \mathrm{L}$ of $10 \mathrm{mM}$ sodium cacodylate buffer ( $\mathrm{pH}$ 7.0), and the solution was transferred to an ampule and sealed. The sealed ampule was then heated in a boiling water bath for $6 \mathrm{~h}$.

d(ATACAAAC), d(ATACCAAA), and d(AAACCATA) [HPLC chromatogram for the separation of the irradiation mixture of d(ATACAAAC) is shown in Figure 1a].

ESI-MS/MS establishes unambiguously that the fraction eluting after the starting material is an ODN carrying a modification on thymine. Negative-ion ESI-MS shows that the product is $14 \mathrm{u}$ more than the unmodified d(ATACCAAA) and the product-ion spectrum of the $[\mathrm{M}-2 \mathrm{H}]^{2-}$ ion establishes that the $14 \mathrm{u}$ mass increment occurs on the thymine residue in d(ATACCAAA) (Figure 2b). Comparing to the unmodified parent (Figure 2a), we observe a new product ion, $\mathrm{w}_{6}$, that is both singly- and doubly-charged. In addition, we observe that the masses of the $\left[\mathrm{a}_{3}-\mathrm{B}_{3}(\mathrm{~A})\right]^{-},\left[\mathrm{a}_{4}-\mathrm{B}_{4}(\mathrm{C})\right]^{-}$, $\left[a_{5}-B_{5}(C)\right]^{-},\left[a_{6}-B_{6}(A)\right]^{-},\left[a_{7}-B_{7}(A)\right]^{2-}$, and $w_{7}^{2-}$ ions increase by $14 \mathrm{u}$, whereas those of the $\mathrm{w}_{1}^{-}, \mathrm{w}_{2}^{-}, \mathrm{w}_{3}^{-}, \mathrm{w}_{4}^{-}$, $\mathrm{w}_{5}^{-}$, and $\mathrm{w}_{6}^{-}\left(\mathrm{w}_{6}^{2-}\right)$ ions remain the same upon the formation of the thymine modification. (The masses for the singly-charged fragment ions of all the ODNs reported in this study are shown in Table 1). The mass 


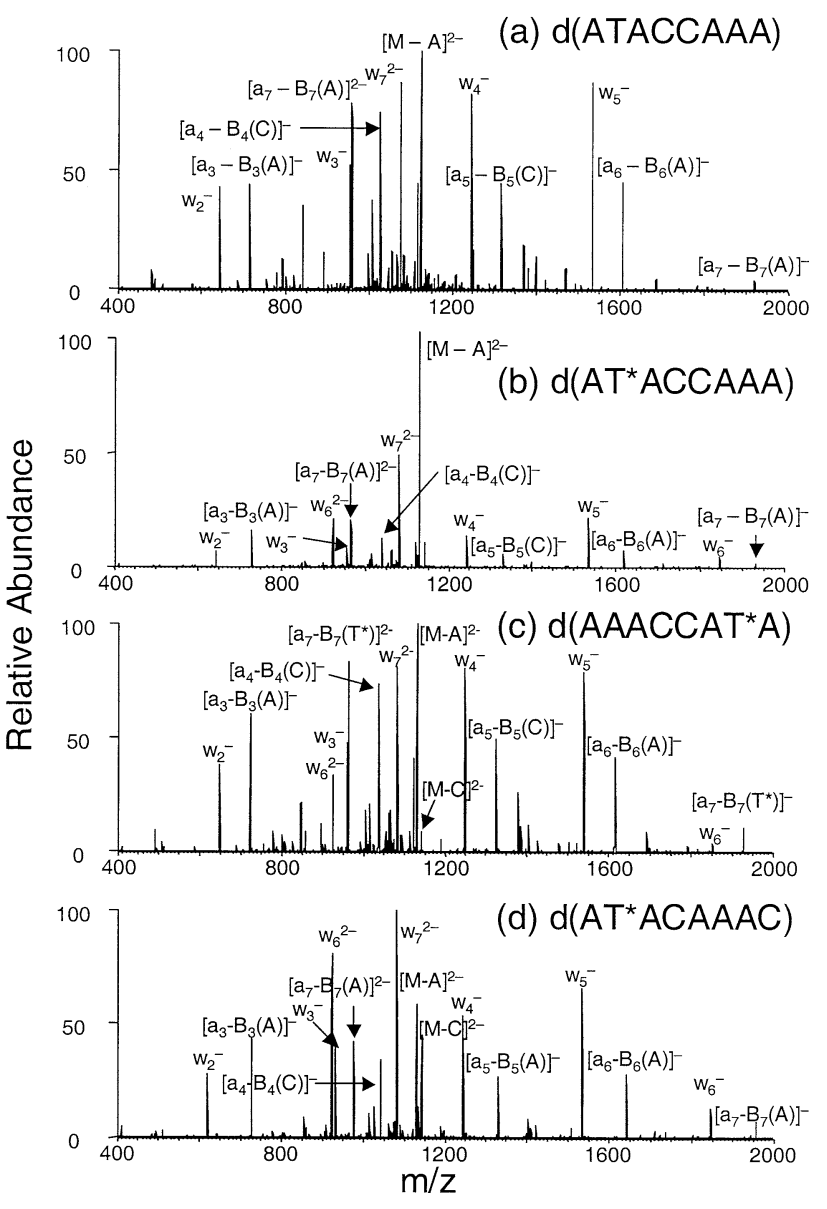

Figure 2. ESI-MS/MS of the $[\mathrm{M}-2 \mathrm{H}]^{2-}$ ions of d(ATACCAAA) (a), d(AT*ACCAAA) (b), d(AAACCAT*A) (c), and $\mathrm{d}\left(\mathrm{AT}^{*} \mathrm{ACAAAC}\right)(\mathbf{d})\left(\mathrm{T}^{*}\right.$ is 5 -formyluracil).

increase of $14 \mathrm{u}$ is consistent with the modification of thymine to 5-formyluracil, a known lesion of thymine induced by ionizing radiation and sensitized photoirradiation [9].

It has been shown previously that the formation of 5 -formyluracil weakens the glycosidic bond, and the modified base can be selectively released from DNA as a free base by heat treatment at physiological $\mathrm{pH}$ [22]. To establish rigorously that the damaged base is 5-formyluracil, we incubated the ODN $\mathrm{d}\left(\mathrm{AT}^{*} \mathrm{ACAAAC}\right.$ ) ( $\mathrm{T}^{*}$ is 5 -formyluracil) in a $50 \mathrm{mM}$ sodium cacodylate buffer ( $\mathrm{pH} 7.0$ ) at $100{ }^{\circ} \mathrm{C}$ for $5 \mathrm{~h}$, and separated the reaction mixture by reverse-phase HPLC.
It turns out that the base released from the hydrolysis of $\mathrm{d}\left(\mathrm{AT}^{*} \mathrm{ACAAAC}\right)$ and the authentic 5 -formyluracil have the same retention time on reverse-phase HPLC, very similar UV absorption spectra (Figure $1 \mathrm{~b}$ and $\mathrm{c}$ ), the same molecular weights and fragmentation patterns in MS/MS (Figure 1d). The two major fragment ions of $\mathrm{m} / \mathrm{z} 69$ and 112 are also present as major fragment ions in the electron-impact MS of 5-formyluracil [23]. Hydrolysis of d(AAACCAT*A) gave similar results (data not shown).

One interesting feature in the product-ion spectrum is that strand cleavage occurs readily 3 ' to the 5 -formyl2 -deoxyuridine and results in the formation of $\mathrm{w}_{6}^{-}$and $\mathrm{w}_{6}^{2-}$ ions (Figure $2 \mathrm{~b}$ ), whereas no cleavage occurs 3 ' to thymidine [10-12, 24, 25]. We then establish the generality of this observation by studying the fragmentation of other ODNs carrying a 5-formyluracil. The production spectra of the $[\mathrm{M}-2 \mathrm{H}]^{2-}$ ions of d(AAACCAT $\left.{ }^{*} \mathrm{~A}\right)$ and $\mathrm{d}\left(\mathrm{AT}^{*} \mathrm{ACAAAC}\right)$ are very similar to that of the $[\mathrm{M}-2 \mathrm{H}]^{2-}$ ion of $\mathrm{d}\left(\mathrm{AT}^{*} \mathrm{ACCAAA}\right.$ ) (Figure $2 \mathrm{c}$ and $\mathrm{d}$ ): We observed mass shifts for certain fragment ions and the shifts are consistent with the modification of thymine to 5-formyluracil. We also observed facile cleavage of the 3' $\mathrm{C}-\mathrm{O}$ bond adjacent to the 5-formyluracil. Careful readers may notice that the relative abundances of the $[\mathrm{M}-\mathrm{C}]^{2-}$ and $[\mathrm{M}-\mathrm{A}]^{2-}$ are different in the three sequences studied. The difference, however, is similar in the MS/MS of the unmodified precursor ODNs (product-ion spectrum of the $[\mathrm{M}-2 \mathrm{H}]^{2-}$ is shown in Figure 2a as an example).

\section{Preparation and ESI-MS/MS Characterization of ODNs Containing a 2-Aminoimidazolone}

$\mathrm{Iz}$ is the major product of guanine in ODN upon one-electron photooxidation [4]. We prepared Iz-containing ODNs, d(TTIzGTA), and d(TTGIzTA), following the procedure reported by Kino and coworkers [4]. It turns out that the product-ion spectra of the two positional isomers are distinctive, and they locate the sites of the 2-aminoimidazolone modification. Similar to the product-ion spectra of the $[\mathrm{M}-2 \mathrm{H}]^{2-}$ ions of ODNs containing a 5-formyluracil, those of ODNs containing Iz show mass shifts for certain fragment ions when compared to the product-ion spectrum of the unmodified precursor (Figure 3). In contrast to the product-ion spectra of ODNs containing an 8-oxoguanine [26], those

Table 1. Calculated masses for the singly-charged fragment ions of ODNs used in this study

\begin{tabular}{|c|c|c|c|c|c|c|c|c|c|c|c|c|c|}
\hline & $\mathrm{w}_{1}$ & $w_{2}$ & $w_{3}$ & $\mathrm{w}_{4}$ & $w_{5}$ & $w_{6}$ & $w_{7}$ & $\begin{array}{c}\mathrm{a}_{2}- \\
\mathrm{B}_{2} \\
\end{array}$ & $\begin{array}{c}\mathrm{a}_{3}- \\
\mathrm{B}_{3} \\
\end{array}$ & $\begin{array}{c}\mathrm{a}_{4}- \\
\mathrm{B}_{4} \\
\end{array}$ & $\begin{array}{l}\mathrm{a}_{5^{-}} \\
\mathrm{B}_{5} \\
\end{array}$ & $\begin{array}{c}a_{6}- \\
B_{6} \\
\end{array}$ & $\begin{array}{l}a_{7}- \\
B_{7} \\
\end{array}$ \\
\hline ATACCAAA & 330 & 643 & 956 & 1245 & 1534 & 1847 & 2151 & 410 & 714 & 1027 & 1316 & 1605 & 1918 \\
\hline $\mathrm{AT}^{*} \mathrm{ACCAAA}$ & 330 & 643 & 956 & 1245 & 1534 & 1847 & 2165 & 410 & 728 & 1041 & 1330 & 1619 & 1932 \\
\hline AAACCAT ${ }^{*}$ A & 330 & 648 & 961 & 1250 & 1539 & 1852 & 2165 & 410 & 723 & 1036 & 1325 & 1614 & 1927 \\
\hline $\mathrm{AT}^{*} \mathrm{ACAAAC}$ & 306 & 619 & 932 & 1245 & 1534 & 1847 & 2165 & 410 & 728 & 1041 & 1330 & 1643 & 1956 \\
\hline TTGGTA & 330 & 634 & 963 & 1292 & 1596 & & & 401 & 705 & 1034 & 1363 & & \\
\hline TTIzGTA & 330 & 634 & 963 & 1253 & 1557 & & & 401 & 705 & 1095 & 1324 & & \\
\hline TTGIzTA & 330 & 634 & 924 & 1253 & 1557 & & & 401 & 705 & 1034 & 1324 & & \\
\hline
\end{tabular}




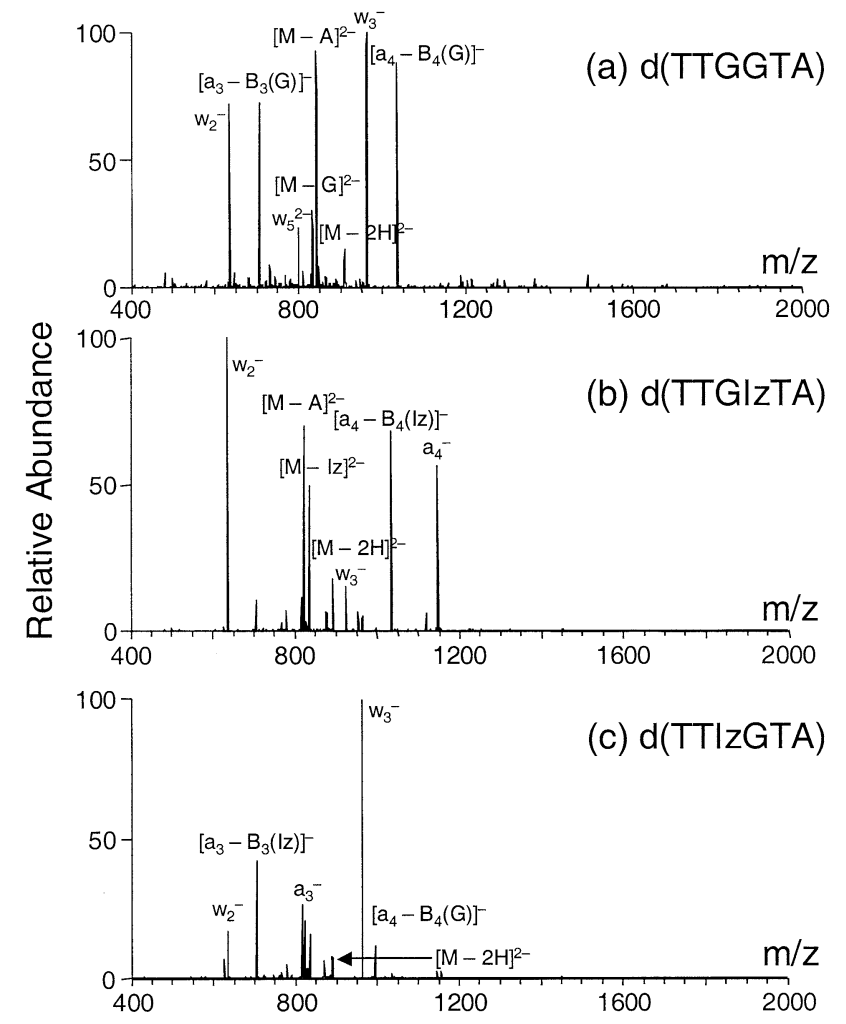

Figure 3. ESI-MS/MS of the $[\mathrm{M}-2 \mathrm{H}]^{2-}$ ions of d(TTGGTA) (a), $\mathrm{d}(\mathrm{TTGIzTA})(\mathbf{b})$, and d(TTIzGTA) (c) (Iz is 2-aminoimidazolone).

of ODNs containing an Iz do show cleavages 3 ' to the modification site, leading to the formation of $\left[\mathrm{a}_{3}-\right.$ $\left.\mathrm{B}_{3}(\mathrm{Iz})\right]^{-}$and $\mathrm{w}_{3}^{-}$ions for $\mathrm{d}(\mathrm{TTIzGTA})$ and $\left[\mathrm{a}_{4}-\mathrm{B}_{4}(\mathrm{Iz})\right]^{-}$ and $\mathrm{w}_{2}^{-}$ions for d(TTGIzTA) (Figure 3).

In addition to the formation of $\mathrm{w}_{\mathrm{n}}$ and $\left[\mathrm{a}_{\mathrm{n}}-\right.$ Base] ions $3^{\prime}$ to the modification, we observe $\mathrm{a}_{3}^{-}$and $\mathrm{a}_{4}^{-}$ions in the product-ion spectra of the $[\mathrm{M}-2 \mathrm{H}]^{2-}$ ions of $\mathrm{d}($ TTIzGTA) and $\mathrm{d}(\mathrm{TTGIzTA})$, respectively. Previously Wang et al. $[25,27]$ reported the formation of $a_{n}$ ions at the 3' side of a photomodification in the product-ion spectra of deprotonated ODN ions containing dimeric DNA photoproducts. The authors attributed the formation of the $a_{n}$ ion to the covalent linkage of the two bases being photocrosslinked, which prevents the formation of the $\left[a_{n}-B a s e\right]$ ion [25, 27]. The formation of the $a_{n}$ ion for the Iz-containing ODNs, however, cannot be rationalized in a similar way and the reason why $a_{n}$ ions were produced at $\mathrm{Iz}$ sites remains not clear at the moment. Likewise we prepared $d(A A A C C A I z A)$ from the photooxidation of $\mathrm{d}$ (AAACCAGA) and the product-ion spectrum of the $[\mathrm{M}-2 \mathrm{H}]^{2-}$ ion of d(AAACCAIzA) gave similar results (data not shown).

\section{The Effect of Charge State on the Fragmentation of ODNs}

Earlier studies by McLuckey and coworkers [13, 20, 21, 28] and recent work by Luo et al. [26] demonstrated that

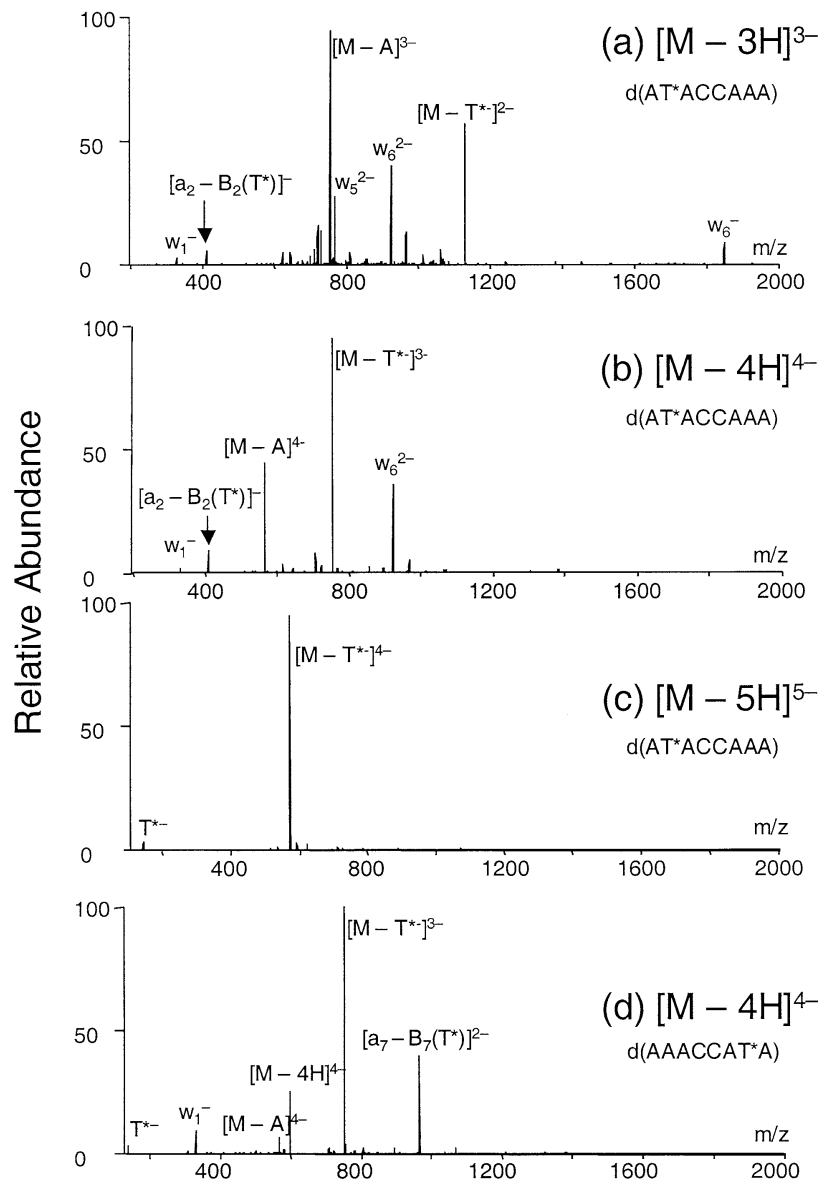

Figure 4. Product-ion spectra of the $[\mathrm{M}-3 \mathrm{H}]^{3-}(\mathbf{a}),[\mathrm{M}-4 \mathrm{H}]^{4-}$ (b), and $[\mathrm{M}-5 \mathrm{H}]^{5-}$ ions of $\mathrm{d}\left(\mathrm{AT}^{*} \mathrm{ACCAAA}\right)$ and the $[\mathrm{M}-4 \mathrm{H}]^{4-}$ ions of $\mathrm{d}\left(\mathrm{AAACCAT}^{*} \mathrm{~A}\right)(\mathbf{d})$.

the most distinctive feature of the fragmentation of deprotonated ODNs at a high charge state is the preferential loss of an adenine base and the consequent strand cleavage 3 ' to adenosine. In addition, the loss of adenine anion becomes more favorable than that of a neutral adenine as the charge state increases $[13,20,21$, 28].

To investigate whether $\mathrm{Iz}$ and 5-formyluracil can affect the fragmentation of ODNs at high charge state, we also acquired the product-ion spectra of deprotonated ions of Iz- and 5-formyluracil-containing ODNs at different charge states. Our results show that the loss of 5-formyluracil as an anion is favored over the loss of adenine as a neutral molecule with the increasing of charge state (Figure $4 a, b$, and c).

The relative ease of the formation of 5-formyluracil anion at high charge state and the resulting strand cleavage 3 ' to the modification site provides a unique opportunity for determining the site of 5-formyluracil modification. This feature of the product-ion spectrum of deprotonated precursor at high charge state is demonstrated in Figure $4 \mathrm{~b}$ and d, which shows the production spectra of the $[\mathrm{M}-4 \mathrm{H}]^{4-}$ ions of two other ODNs, $\mathrm{d}\left(\mathrm{AT}^{*} \mathrm{ACCAAA}\right)$ and $\mathrm{d}\left(\mathrm{AAACCAT}{ }^{*} \mathrm{~A}\right)$. Both production spectra show that the most predominant cleavages 
occur at the site 3 ' to the 5-formyluracil residue. Comparing to the product-ion spectrum of the $[\mathrm{M}-2 \mathrm{H}]^{2-}$ ion, the product-ion spectrum of the $[\mathrm{M}-4 \mathrm{H}]^{4-}$ ion is equally useful in determining the site of the 5 -formyluracil modification, though the latter is much simpler in interpretation. The product-ion spectrum of the [M $5 \mathrm{H}]^{5-}$ ion (Figure $4 \mathrm{c}$ ), however, only shows fragment ions resulting from charge splitting process, i.e., 5 -formyluracil anion $\left(\mathrm{T}^{*-}\right)$ and the complementary $\left[\mathrm{M}-\mathrm{T}^{*-}\right]^{4-}$ ion.

We also acquired the product-ion spectra of the $[\mathrm{M}-$ $3 \mathrm{H}]^{3-}$ and $[\mathrm{M}-4 \mathrm{H}]^{4-}$ ions of d(AAACCAIzA), and the results show that adenine is preferred over Iz in loss as a neutral or anionic base (data not shown). The reason why adenine is favored over guanine, cytosine, and thymine and why 5-formyluracil is favored over adenine in loss as anion from deprotonated ODN at high charge states awaits further investigation.

\section{Conclusions}

We isolated 2-aminoimidazolone- or 5-formyluracilcontaining hexa- and/or octonucleotides from riboflavin-sensitized photoirradiation mixtures of those ODN precursors. Product-ion spectra of deprotonated ions of those ODNs show that cleavages occur 3' to the 2-aminoimidazolone and 5-formyluracil sites. Those cleavages indicate the sites of modifications. The result is in contrast to the CAD of the deprotonted ions of ODNs bearing an 8-oxoguanine, where cleavage doesn't occur 3 ' to the modification site [26].

We further collisionally activated the 5-formyluracilcontaining ODNs with different charge states and our results showed that, at high charge states, the loss of 5 -formyluracil anion is more facile than the loss of neutral or anionic adenine. Further studies are underway to rationalize why 5-formyluracil and 8-oxoguanine give different cleavage characteristics from their unmodified parents and why the base losses for highly deprotonated ODN ions follow the order of 5-formyluracil is favored over adenine, which is favored over the loss of other bases, at high charge state.

\section{Acknowledgments}

The authors acknowledge the NIH (grant no. CA 96906) and the University of California at Riverside for supporting this research.

\section{References}

1. von Sonntag, C.; Schuchmann, H. P. Int. J. Radiat. Biol. Relat. Stud. Phys. Chem. Med. 1986, 49, 1-34.

2. Cadet, J.; Vigny, P. Morrison, H., Ed. In Bioorganic Photochemistry, Vol. I. John Wiley: New York, 1990; pp 1-272.

3. Steenken, S. Chem. Rev. 1989, 89, 503-520.

4. Kino, K.; Saito, I.; Sugiyama, H. J. Am. Chem. Soc. 1998, 120, 7373-7374.

5. Decarroz, C.; Wagner, J. R.; Van Lier, J. E.; Krishna, C. M.; Riesz, P.; Cadet, J. Int. J. Radiat. Biol. Relat. Stud. Phys. Chem. Med. 1986, 50, 491-505.

6. Douki, T.; Cadet, J. Int. J. Radiat. Biol. 1999, 75, 571-581.

7. Kino, K.; Sugiyama, H. Chem. Biol. 2001, 8, 369-378.

8. Privat, E. J.; Sowers, L. C. Mutat. Res. 1996, 354, 151-156.

9. Bjelland, S.; Anensen, H.; Knaevelsrud, I.; Seeberg, E. Mutat. Res. 2001, 486, 147-154.

10. Wan, K. X.; Gross, M. L. J. Am. Soc. Mass Spectrom. 2001, 12, $580-589$.

11. Wan, K. X.; Gross, J.; Hillenkamp, F.; Gross, M. L. J. Am. Soc. Mass Spectrom. 2001, 12, 193-205.

12. Gross, J.; Hillenkamp, F.; Wan, K. X.; Gross, M. L. J. Am. Soc. Mass Spectrom. 2001, 12, 180-192.

13. McLuckey, S. A.; Van Berkel, G. J.; Glish, G. L. J. Am. Soc. Mass Spectrom. 1992, 3, 60-70.

14. Liguori, A.; Napoli, A.; Sindona, G. J. Mass Spectrom. 2000, 35, 139-144.

15. Liguori, A.; Napoli, A.; Sindona, G. Rapid Commun. Mass Spectrom. 1994, 8, 89-93.

16. Greco, F.; Liguori, A.; Sindona, G.; Uccella, N. J. Am. Chem. Soc. 1990, 112, 9092-9096.

17. Cooks, R. G.; Wong, P. S. H. Acc. Chem. Res. 1998, 31, 379-386.

18. Wang, Y.; Taylor, J. S.; Gross, M. L. J. Am. Soc. Mass Spectrom. 2001, 12, 550-556.

19. Wang, Y.; Taylor, J. S.; Gross, M. L. J. Am. Soc. Mass Spectrom. 2001, 12, 1174-1179.

20. McLuckey, S. A.; Habibi-Goudarzi, S. J. Am. Chem. Soc. 1993, 115, 12085-12095.

21. McLuckey, S. A.; Habibi-Goudarzi, S. J. Am. Soc. Mass Spectrom. 1994, 5, 740-747.

22. Bjelland, S.; Eide, L.; Time, R. W.; Stote, R.; Eftedal, I.; Volden, G.; Seeberg, E. Biochemistry 1995, 34, 14758-14764.

23. Ulrich, J.; Teoule, R.; Massot, R.; Cornu, A. Org. Mass Spectrom. 1969, 2, 1183-1199.

24. Wang, Z.; Wan, K. X.; Ramanathan, R.; Taylor, J. S.; Gross, M. L. J. Am. Soc. Mass Spectrom. 1998, 9, 683-691.

25. Wang, Y.; Taylor, J. S.; Gross, M. L. J. Am. Soc. Mass Spectrom. 1999, 10, 329-338.

26. Luo, H.; Lipton, M. S.; Smith, R. D. J. Am. Soc. Mass Spectrom. 2002, 13, 195-199.

27. Wang, Y.; Taylor, J. S.; Gross, M. L. Chem. Res. Toxicol. 2001, 14, $738-745$.

28. Habibi-Goudarzi, S.; McLuckey, S. A. J. Am. Soc. Mass Spectrom. 1995, 6, 102-113. 